\title{
Bridging the gap between air pollution models and epidemiological studies
}

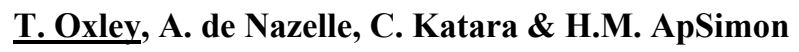 \\ Centre for Environmental Policy, Imperial College, South Kensington, London SW7 1NA, United Kingdom \\ Email: t.oxley@imperial.ac.uk
}

\begin{abstract}
Air pollution models developed for policy support have traditionally generated aggregated population exposure metrics - such as population weighted mean concentrations, years-of-life-lost or disability-adjusted-life-years - as a proxy for impacts upon human health. With the latter also using results from epidemiological studies, these metrics are useful for gauging whether policies potentially reduce health impacts, but they do not account for the movement of individuals, and air pollution models could provide more focussed information for evaluating real-world health impacts. However, annualised air pollution models can describe the spatial variation of different pollutants for use in health impact assessments based upon daily activity patterns of individuals.

Focussing on airborne particulate matter (PM), we acknowledge that there is no consensus on the relative toxicity of different components of PM, with reviews by the WHO investigating various causative mechanisms, implying specific components as particularly toxic, such as diesel particulates which are also identified as a carcinogen. Recognising that epidemiological studies already utilise outputs from air pollution models, we highlight the complexity of airborne PM in relation to size fractions, species composition, source attribution, control of emissions, and health impacts, and show how air pollution models can provide more focussed information to benefit epidemiological assessments.

Drawing on work attributing health effects to individual PM constituents, and source apportionment by the UK Integrated Assessment Model, we are able to distinguish the spatial distribution of concentrations of components which may have differing impacts upon human health. Understanding these spatial variations and their coincidence with vulnerable populations (eg. schools or hospitals) represents a step towards air pollution models providing outputs of greater utility for epidemiological studies.

With the emphasis upon reducing health impacts under the Directive on ambient air quality and cleaner air for Europe, the provision of more focussed metrics within air pollution models should enable policy makers to direct abatement strategies towards the industrial and residential sectors with the greatest combined impact on human health, simultaneously providing better data for epidemiological studies evaluating the impacts upon mobile populations.
\end{abstract}

Keywords: $\quad P M_{2.5}$, Health Impacts, Population Exposure, Integrated Assessment 


\section{INTRODUCTION}

Airborne particulate matter (PM) and assessment of the effects of exposure to PM on human health represents a particularly complex field of investigation for the evaluation of air pollutant emission abatement strategies. In-depth studies have been carried out both at the national scale to understand more fully the sources of and spatial distribution of PM [AQEG, 2012] and internationally to investigate the evidence for adverse health effects [WHO 2012; 2013], with a plethora of exposure and epidemiological studies, and investigations into the mechanistic and pathophysiological pathways that describe the connections between airborne PM and health (eg Pope \& Dockery (2006); Schlesinger (2007); Rohr \& Wyzga (2012)).

The complexity of this field of investigation is further emphasised by the variable size fractions of PM, ranging from coarse particles $\left(\mathrm{PM}_{10}\right.$, subject to air quality legislation in the form of roadside air quality limit values), fine particles $\left(\mathrm{PM}_{2.5}\right.$, subject to controls on background concentrations), and ultra-fine and nanoparticles which have been the subject of extensive research both regarding concentrations [Kaur et al., 2007] and human exposure due to the increased potential of particles to deeply penetrate the lungs [Donaldson et al., 2001]. This work focusses on fine particles $\left(\mathrm{PM}_{2.5}\right)$ since the legislation to control $\mathrm{PM}_{2.5}$ includes targets to reduce population exposure to background concentrations (Directive 2008/50/EC).

Within each of these size fractions of PM, consideration must also be given to the speciation of the total mass since different 'species' may be linked to specific health effects from exposure [WHO, 2013], or display toxic characteristics [Kelly \& Fussell, 2012]. Whereas control of particulates and assessment of alternative pollution abatement strategies [Oxley et al., 2012; 2013] tends to focus upon the total mass, different species may be emitted by different sources both in relation to primary PM (eg. diesel, black carbon, metals etc.) and precursor emissions of secondary inorganic aerosols (ie. $\mathrm{NH}_{3}, \mathrm{SO}_{2}$ and $\mathrm{NO}_{\mathrm{X}}$ emissions). These variable contributions to the total mass are presented in Figure 1, highlighting the significant contributions of shipping and European emissions to aerosol concentrations in the UK. In order to calculate the total mass, background concentrations (sea-salt, dust, organic aerosols etc.), which vary widely across the country, must be included. The concentrations shown reflect population weighted mean concentrations calculated nationally; it is important to note, in relation to abatement strategies, that the spatial distribution of emission sources will result in contrasting source attribution in different regions. The effects of different spatial distribution of emissions is highlighted in Figure 2 which spatially contrasts the concentrations resulting from road transport (cars) and domestic combustion; whereas domestic combustion has a slightly greater impact upon aerosol concentrations, road transport has a significantly greater impact upon primary $\mathrm{PM}_{2.5}$ in urban areas.

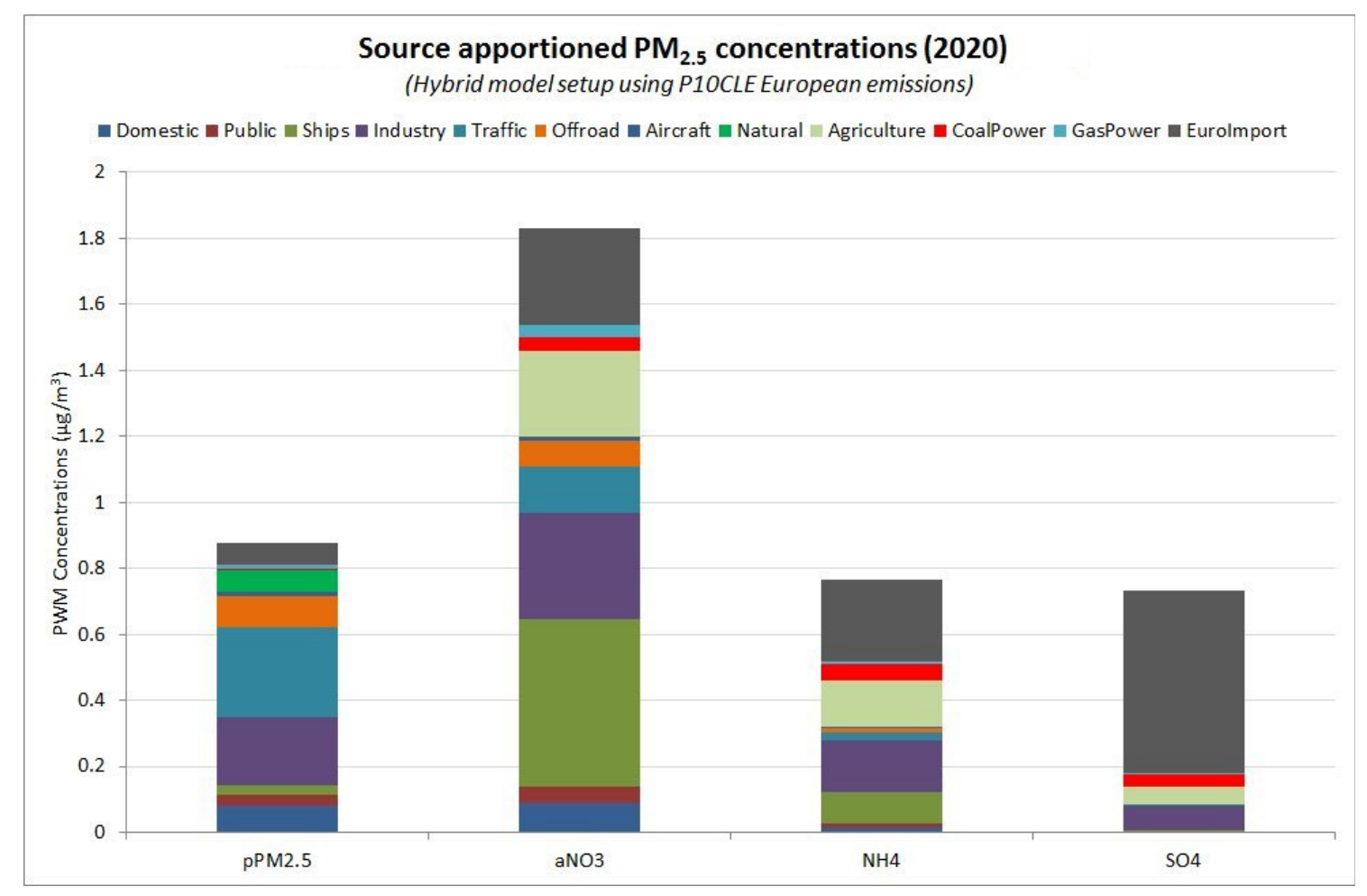

Figure 1 - Anthropogenic emissions of air pollutants contribute contrasting proportions of primary $\mathrm{PM}_{2.5}$ and secondary inorganic aerosols (SIA) depending upon the source of the emissions 
The final complication to assessment of health impacts is the presumption in annualised integrated assessment models that populations are static at their place of residence; it is this spatial distribution of the human population that provides the basis of calculations of population exposure. However, although this metric may have utility for assessing alternative abatement strategies [Oxley et al., 2012], it says little about the real-world exposure of individuals who may spend only a third of their day at their place of residence, with much of that time spent indoors and therefore exposed to different sources (cooking, cigarette smoke etc.) and not the presumed ambient outdoor concentration. It is for such reasons that complementary studies have been carried out to assess air pollution exposures as a function of daily patterns of activity such as travel behaviours, contrasting the results to exposure assignment methods typically used in epidemiologic studies [de Nazelle et al., 2009; 2013], and broader health impact assessment (HIA) models have been developed attempting to quantify health benefits of active travel policies, accounting for impacts on air pollution exposures, physical activity and traffic injuries [RojasRueda et al., 2011; 2012].
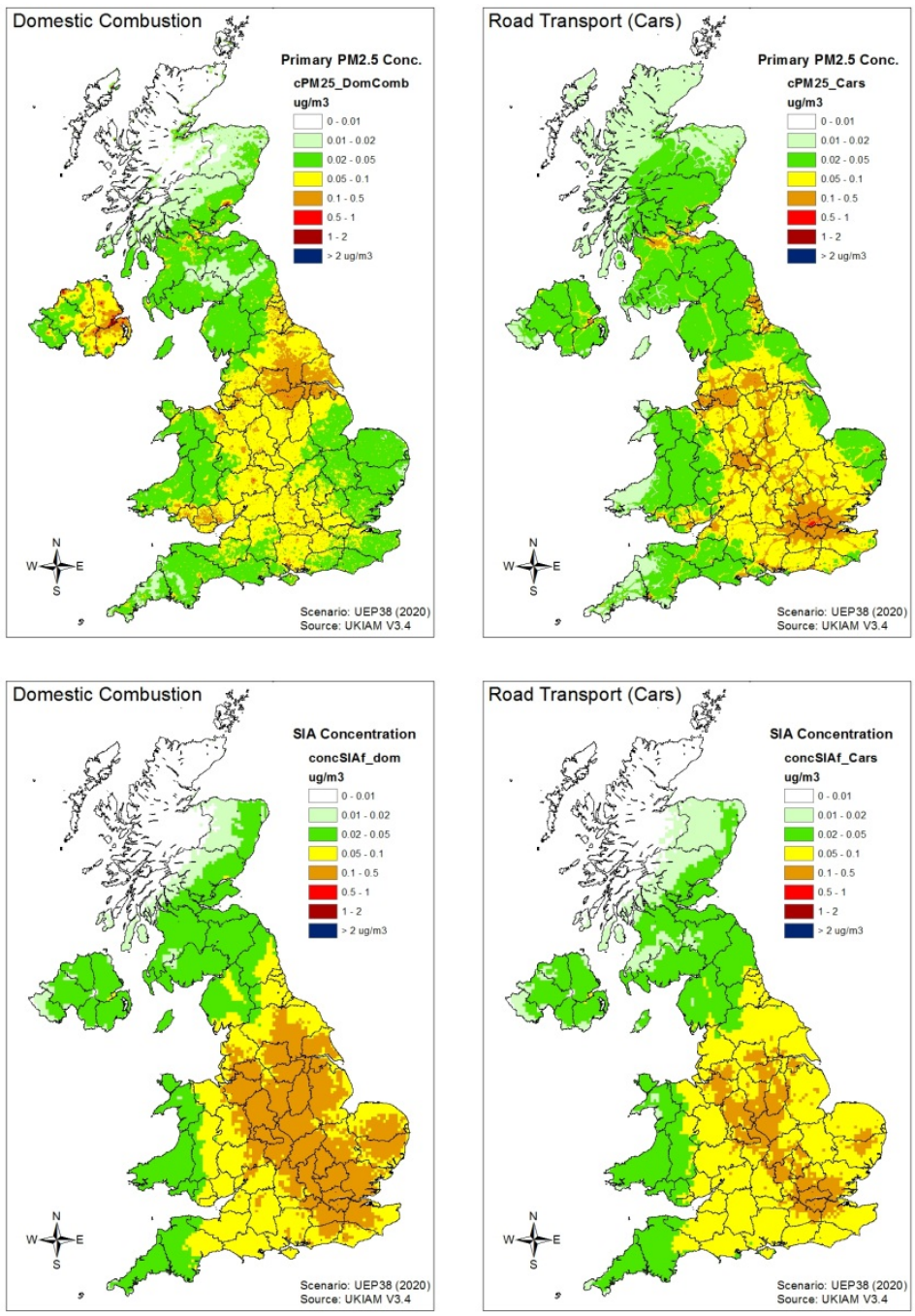

Figure 2 - Contrasting spatial distributions of primary $\mathrm{PM}_{2.5}$ and secondary inorganic aerosol (SIA) concentrations resulting from domestic combustion and road transport (cars).

It should be emphasised that the study presented here is based upon outputs from the UK Integrated Assessment Model which reflect annual average concentrations, whereas detailed temporal patterns are required to fully investigate the impacts of, for example, rush hour traffic when going to and from work. More detailed modelling with models like ADMS (www.cerc.co.uk) or CMAQ (www.cmaq-model.org), with an hourly resolution, have routinely been used in an epidemiological context. Furthermore, there have been a variety of complementary studies, for example carried out with portable monitors, or on selected cohorts of people to investigate the incidence of lung cancer across Europe [Raaschou-Nielsen et al., 2013].

\section{DIRECTIVE 2008/50/EC}

Directive 2008/50/EC of the European Parliament on ambient air quality and cleaner air for Europe has merged most of the preceding legislation into a single directive (except for the fourth daughter directive), with no change to existing air quality objectives. The Directive specifies new air quality objectives for $\mathrm{PM}_{2.5}$ (fine particles), including limit values and exposure related objectives - with exposure concentration obligations and exposure reduction targets. It further allows discounting of natural sources of pollution when assessing compliance against limit values.

In essence, measurements of background concentrations of $\mathrm{PM}_{2.5}$ provide the basis for assessing compliance with indicative limit values, supplemented by modelling to evaluate achievement of the $15 \%$ exposure reduction targets based upon population agglomerations; with large urban areas, suitable monitoring stations for $\mathrm{PM}_{2.5}$ are required which can be used as an indicator of change. In parallel, there are discussions on whether and how modelling can be employed to quantify exposure reductions. With models validated against 
measurements, the utilisation of modelling will necessarily assume that the monitoring stations are suitably representative of their specified agglomeration. In this study we have treated individual London boroughs as separate agglomerations in order to better understand the implications of modelling exposure reductions, but it should be noted that these are smaller than the agglomerations defined by the Directive

With an explicit objective of reducing population exposure to $\mathrm{PM}_{2.5}$, emission abatement strategies need to be carefully focussed with consideration of the portion of the total mass which can be affected. Although the balance of contributions will vary depending upon the spatial location, assuming national scale population weighted mean concentrations (Figure 1), approx. 50\% of the total mass comes from 'natural' sources which cannot be abated, up to $40 \%$ may be secondary inorganic aerosols, SIA, of which a third may be from transboundary sources, with little more than $10 \%$ comprised of primary $\mathrm{PM}_{2.5}$ and including possible toxic components. Therefore, in the context of an urban environment such as London, reducing the contribution of transboundary or national abatement measures may be as effective in reducing overall $\mathrm{PM}_{2.5}$ concentrations as abatement of local sources; however local or regional measures focussed on primary PM emissions will influence the different species of concern (eg. diesel, black carbon etc.), with measures affecting SIA influencing the total mass.

\section{HEALTH IMPACTS OF PARTICULATE MATTER}

Epidemiological and toxicological studies have shown a need to consider the role of both the chemical composition (such as transition metals or combustion-derived primary and secondary organic particles) and the physical properties (size, particle number and surface area) of $\mathrm{PM}_{10}, \mathrm{PM}_{2.5}$ and ultrafine particles, in order to better understand the health impacts of particulate matter [Peters, 2013].

With the adverse effects on health of particulate matter especially well documented, and no evidence of a safe level of exposure or a threshold below which no adverse health effects occur [WHO, 2013], the review of evidence on health aspects of air pollution (REVIHAAP) notes that "exposure to air pollutants is largely beyond the control of individuals and requires action by public authorities at the national, regional and international levels", based on a multi-sectoral approach to develop and effectively implement long-term policies that reduce the health impacts of air pollution.

With extensive research having been carried out into the health effects of particulate matter (eg. Donaldson et al., 2001; Pope et al., 2001; Schlesinger, 2007; Rohr \& Wyzga, 2012), REVIHAAP investigated what new evidence has emerged with regard to the health impacts of $\mathrm{PM}_{2.5}$, in particular evidence on the role of different components of PM - size fractions, black carbon, chemical constituents etc. - in relation to adverse health impacts.

Considering that different emission sources will contribute contrasting amounts of these different components of PM, integrated assessment models are ideally suited to quantifying the spatial distribution of these constituents in relation to the total mass of airborne particulate matter. In this study the UK Integrated Assessment Model [Oxley et al., 2013] quantifies the source-attribution of concentrations at each monitoring station location. However, although the UKIAM subsequently derives population exposure based upon residential populations, which is useful for assessing alternative pollution abatement strategies, studies focussing upon individual exposures which capture daily activity patterns and mobile populations (for example de Nazelle et al. (2013)) will find more utility in the spatial representations of source-apportioned concentrations.

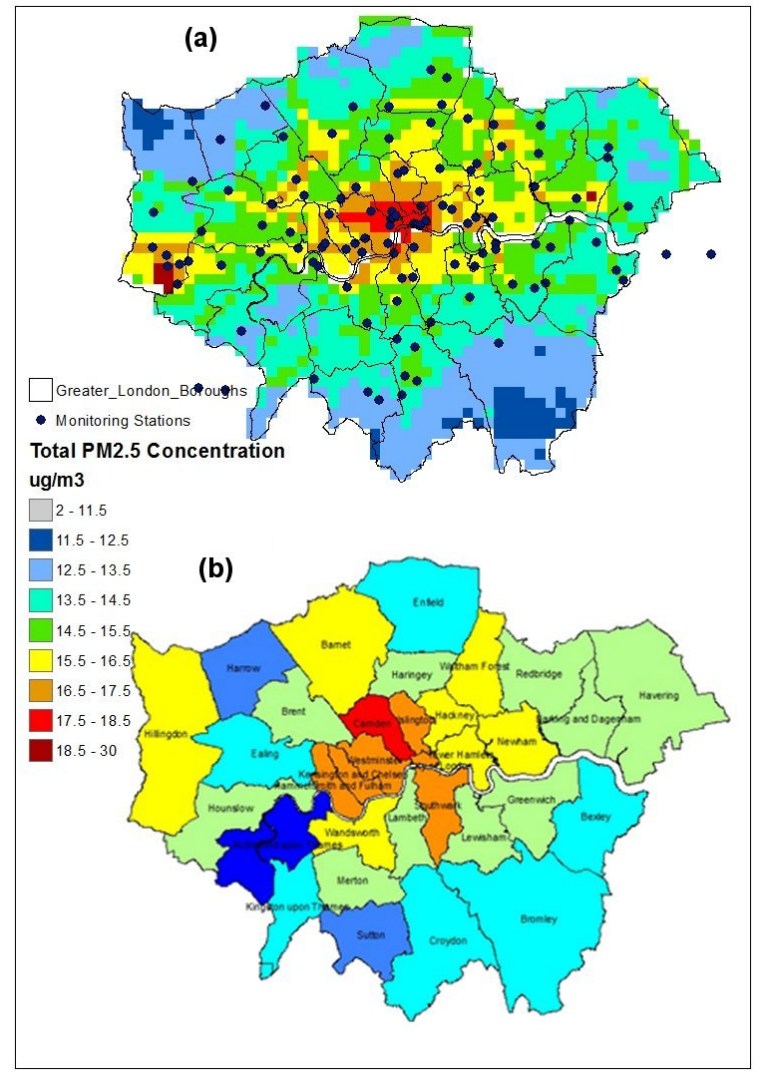

Figure 3 - Much of the spatial distribution of (a) gridded concentrations may be lost when (b) monitoring locations are assumed to be representative of a borough. 


\section{SENSITIVITY SCENARIOS}

The UK Integrated Assessment Model and BRUTAL road transport sub-model provide the basis of the calculations presented in this study [Oxley et al., 2012; 2013]. Validation of the representations provided by these models has been the subject of a model inter-comparison exercise which also evaluated the performance of other air quality models use by Defra [Carslaw, 2011]. This model inter-comparison utilised a baseline scenario for 2010 for direct comparison with measurements from the London air quality monitoring network (www.londonair.org.uk), together with two sensitivity scenarios reflecting, firstly, a $30 \%$ reduction in emissions from road transport, and secondly, a 30\% reduction in emissions from public and domestic combustion.

Whereas Carslaw (2011) evaluated the modelled concentrations at specific monitoring locations, the objective of the study presented here is to investigate the potential for exposure reduction in the context of Directive 2008/50/EC, thus assuming that the concentrations at monitoring sites were representative of concentrations throughout the local borough. The monitoring stations selected include all the background sites, thus excluding roadside and kerbside locations. Where a borough contains multiple stations, the average of these concentrations is assumed to be representative; extreme concentrations (outliers in the dataset, for example at Heathrow Airport) were removed from the analysis. On this basis, the realistic spatial variation in modelled concentrations disappears, to be replaced by homogenous representations which vary by borough.

This change in the spatial representation of concentrations is highlighted in Figure 3 where a similarity is evident at the scale of London as a whole, but which is completely lost at the borough level; hence the importance of ensuring monitoring locations are suitably representative of the local area. Further studies could be carried out to investigate the extent to which exposure calculations at the borough level compare with exposure calculations at the grid scale, which may help in identifying monitoring sites which are suitably representative.

In this study we present results at the borough level using residential populations to highlight how reducing emissions from one sector may be more beneficial than another sector for different boroughs. Where boroughs may have responsibility for local air quality management, this can inform where more detailed modelling may be useful (for example, using ADMS at busy road intersections).

Elsewhere, this borough level approach has been extended to explore how the exposure calculations may vary when daily activity patterns are considered - introducing roadside monitoring sites into the calculations, for example, when travelling to work - with employment distributions providing the basis for daytime exposure. Extension of the exposure calculations in this way moves towards the development of exposure metrics which can be more readily utilised in health impacts assessments [Katara, 2013].
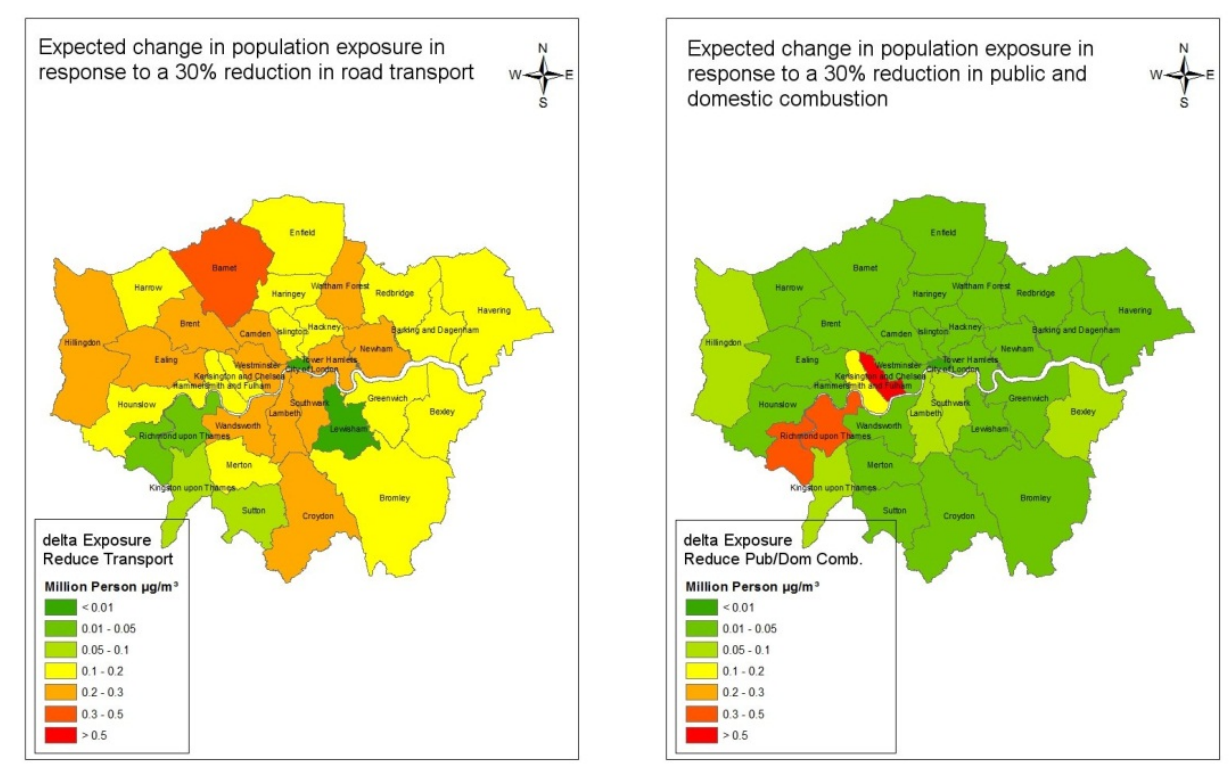

Figure 4 - Estimated changes in population exposure across London, mapped by borough, highlighting the contrasting impact on exposure between reductions in road transport and public/domestic combustion. 


\section{RESULTS}

Model outputs for these sensitivity scenarios included both mapped concentrations (displaying the spatial variation at $1 \mathrm{~km}$ resolution) and source-apportionment of concentrations at the monitoring locations. This study utilised the latter as representative of the borough containing the monitoring station (as presented in Figure 3). Mapping the results in this fashion enables estimation of the change in concentrations in a borough resulting from a 30\% reduction in either road transport or public and domestic combustion, and therefore estimation of the impact of these changes upon population exposure. These variations in exposure are presented in Figure 4, highlighting the different impacts implied in each London borough.

Immediately apparent in these results is the contrasting influence of the two scenarios upon population exposure; this highlights the boroughs where the impact of the different sources coincides with areas of high population. For example, where concentrations are the highest (eg. City of London - see Figure 3) the impact of a reduction in road transport on exposures is the lowest $\left(<0.01\right.$ million person. $\left.\mu \mathrm{g} / \mathrm{m}^{3} / \mathrm{yr}\right)$ because of the small residential population in the City; in contrast, where there are 'average' concentrations in Barnet, population exposure is reduced by more than $0.3 \mathrm{M}$ pers. $\mu \mathrm{g} / \mathrm{m}^{3} / \mathrm{yr}$, reflecting the coincidence of high traffic emissions (both the M1 and the A406 run through the borough) and high residential population densities.

The reduction in public and domestic combustion, however, suggests a reduction in population exposure of less than $0.05 \mathrm{M}$ pers $\mu \mathrm{g} / \mathrm{m}^{3} / \mathrm{yr}$ in Barnet, but up to $1 \mathrm{M}$ pers. $\mu \mathrm{g} / \mathrm{m}^{3} / \mathrm{yr}$ in Kensington \& Chelsea. These sensitivity scenarios therefore clearly highlight the potential spatial variability of emissions abatement upon population exposure, depending upon where the abatement strategies are focussed - in this case, focussed upon road transport or public/domestic combustion.

Additional sensitivity scenarios could be evaluated for different source categories (such as industrial combustion or shipping), which would be expected to result in further contrasting representations of the benefits of abatement in relation to population exposure. The scenarios presented here, with abatement of emissions in key sectors (see Figure 1), highlights the importance of focussing emission reduction strategies on sources where the greatest contributions to concentrations of $\mathrm{PM}_{2.5}$ coincide with population centres.

\section{DISCUSSION \& CONCLUSIONS}

This study set out to bridge the gap between representations of population exposure by annualised integrated assessment models - which have utility in assessing alternative pollution abatement strategies - and the assessment of real-world health impacts of air pollution upon mobile populations. We have highlighted through the literature the extent of the complex connections between particle size and toxicity, emission sources and the spatial variability of airborne particle concentrations, and the health impacts of different constituents of PM.

There remain shortcomings in exposure calculations using annualised representations, but there are benefits where integrated assessment models can source-apportion contributions spatially, and further account for changes in regional or transboundary contributions, where more detailed local scale/urban models often assume spatially homogenous contributions from distant sources, but capture hourly variations at a fine spatial

Table 1 : Advantages and disadvantages of different approaches to exposure assessment

\begin{tabular}{|c|c|c|}
\hline & \multicolumn{2}{|l|}{ assessment } \\
\hline & Advantages & Disadvantages \\
\hline $\begin{array}{l}\text { Integrated } \\
\text { Assessment } \\
\text { Models }\end{array}$ & $\begin{array}{l}\text { Source Apportionment } \\
\text { Rapid Scenario Assessment } \\
\text { Treatment of distant sources } \\
\text { Projected (Future) Scenarios }\end{array}$ & $\begin{array}{l}\text { Annual timestep } \\
\text { Poor resolution }(1 \mathrm{~km}) \\
\text { Residential Population }\end{array}$ \\
\hline $\begin{array}{l}\text { High Resolution } \\
\text { Modelling }\end{array}$ & $\begin{array}{l}\text { High Resolution }(<10 \mathrm{~m}) \\
\text { Hourly timestep } \\
\text { Detailed Meteo/Chemistry }\end{array}$ & $\begin{array}{l}\text { Treatment of distant sources } \\
\text { Long model runtime }\end{array}$ \\
\hline $\begin{array}{l}\text { Mobile } \\
\text { Monitors \& } \\
\text { Cohort Studies }\end{array}$ & $\begin{array}{l}\text { Real-time concentrations } \\
\text { Individual exposure }\end{array}$ & $\begin{array}{l}\text { No source-attribution } \\
\text { Time consuming } \\
\text { Small scale studies } \\
\text { Limited sample } \\
\end{array}$ \\
\hline $\begin{array}{l}\text { Routine } \\
\text { Monitoring }\end{array}$ & $\begin{array}{l}\text { Legal requirement } \\
\text { Standard methods }\end{array}$ & $\begin{array}{l}\text { Representativeness of regions } \\
\text { No source apportionment }\end{array}$ \\
\hline
\end{tabular}
resolution. Table 1 highlights advantages and disadvantages of selected approaches to estimating population exposure.

In the context of Directive 2008/50/EC, this study has utilised source-apportioned spatialised concentrations of $\mathrm{PM}_{2.5}$ calculated by the UK Integrated Assessment Model. Two sensitivity scenarios, providing an indication of the spatial variability of benefits in relation to exposure, show the contrasting benefits of reducing emissions from road transport or domestic combustion. 
In summary, we highlight:

- The importance of monitoring stations used for compliance purposes being suitably representative of the local area;

- Health impacts are complex and depend upon both particle size and chemical composition;

- Different sources contribute contrasting amounts of components of total PM mass (particle size and chemical composition)

- Reduction of emissions from different sources/sectors will affect population exposure to a greater or lesser extent depending upon the spatial locations of both the source and the population;

- Understanding connection between sources, speciation and spatial impact helps to focus exposure reduction strategies on specific sources and sectors;

- Population exposure based upon static populations - useful for assessing abatement strategies remains disconnected from the exposure of mobile individuals and real-world health effects

\section{REFERENCES}

AQEG (Air Quality Expert Group), 2012, Fine Particulate Matter $\left(\mathrm{PM}_{2.5}\right)$ in the United Kingdom, Report to Defra, http://uk-air.defra.gov.uk/library/aqeg/

Carslaw, D.C., 2011, Defra urban model evaluation analysis - Phase 1, Report to Defra, Environmental Research Group, King's College London, $15^{\text {th }}$ April 2011, http://uk-air.defra.gov.uk/library/

Katara, C., 2013, A Critical review of the policy framework for fine particulate matter $\left(\mathrm{PM}_{2.5}\right)$ : why is the current air strategy in the UK not the most health promoting? MSc Thesis, Centre for Environmental Policy, Imperial College London

de Nazelle, A., Rodríguez, D.A., Crawford-Brown, D., 2009, The built environment and health: Impacts of pedestrianfriendly designs on air pollution exposure, Science of The Total Environment 407, 2525-2535

de Nazelle, A., Seto, E., Donaire-Gonzalez, D., Mendez, M., Matamala, J., Nieuwenhuijsen, M. \& Jerrett, M, 2013, Improving estimates of air pollution exposure through ubiquitous sensing technologies. Environmental Pollution 176, 92-99

Donaldson, K., Stone, V., Clouter, A., Renwick, L. \& MacNee, W., 2001, Ultrafine particles, Occup. Environ. Med., 58, 211-216

Donaldson, K., Stone, V., Seaton, A. \& MacNee, W., 2001, Ambient particle inhalation and the cardiovascular system: Potential mechanisms, Environmental Health Perspectives, 109(4), 523-527

Kaur, S., Nieuwenhuijsen, M. \& Colvile, R., 2007, Fine particulate matter and carbon monoxide exposure concentrations in urban street transport microenvironments, Atmospheric Environment, 41, 4781-4810

Kelly, F.J. \& Fussell, J.C., 2012, Size, source and chemical composition as determinants of toxicity attributable to ambient particulate matter, Atmospheric Environment, 60, 504-526

Oxley, T., Dore, A.J., ApSimon, H.M., Hall, J. \& Kryza, M., 2013, Modelling future impacts of air pollution using the multi-scale UK Integrated Assessment Model, Environment International, DOI: 10.1016/j.envint.2013.09.009

Oxley, T., Elshkaki, A., Kwiatkowski, L., Castillo, A., Scarbrough, T. \& ApSimon, H., 2012, Pollution abatement from road transport: cross-sectoral implications, climate co-benefits and behavioural change, Environmental Science \& Policy, 19-20, pp16-32

Peters, A., 2013, Health Effects of Ambient Air Pollution: Scientific and Policy Challenges in dealing with Complex Mixtures, Saltsjöbaden V Workshop 'Taking international air pollution policies into the future', Gothenburg, Sweden 24-26 June 2013, http://www.saltsjobaden5.ivl.se/

Pope, C., Burnett, R., Thun, M., Calle, E., Krewski, D., Ito, K. \& Thurston, D., 2001, Lung cancer, cardiopulmonarymortality, and long-term exposure to fine particulate air pollution, Journal of the American Medical Association, 287(9), 1132-1141

Pope, C.A. \& Dockery, D.W., 2006, Health effects of fine particulate air pollution: Lines that connect, J. Air \& Waste Manage. Assoc., 56, 709-742

Raaschou-Nielsen, O., (and 58 others), 2013, Air pollution and lung cancer incidence in 17 European cohorts: prospective analyses from the European Study of Cohorts for Air Pollution Effects (ESCAPE), Lancet Oncol., 14(9), 813-22

Rohr, A.C. \& Wyzga, R.E., 2012, Attributing health effects to individual particulate matter constituents, Atmospheric Environment, 62, 130-152

Rojas-Rueda, D., de Nazelle, A., Tainio, M., Nieuwenhuijsen, M.J., 2011, The health risks and benefits of cycling in urban environments compared with car use: health impact assessment study. BMJ 343:d425

Rojas-Rueda, D., de Nazelle, A., Teixido, O., Nieuwenhuijsen, M.J., 2012, Replacing car trips by increasing bike and public transport in the greater Barcelona metropolitan area: A health impact assessment study. Environment International 49, 100-109

Schlesinger, R.B., 2007, The health impact of common inorganic components of fine particulate matter $\left(\mathrm{PM}_{2.5}\right)$ in ambient air: a critical review, Inhalation Toxicology, 19, 811-832

WHO, 2012, Health effects of Black Carbon, World Health Organisation, ISBN 978-92-890-0265-3

WHO, 2013, Review of evidence on health aspects of air pollution - REVIHAAP Project: Technical Report, World Health Organisation, http://www.euro.who.int/ 